\title{
The Role of Perceived Social Support in the Relationship Between Being Bullied and Mental Health Difficulties in Adolescents
}

\author{
Nathalie Noret ${ }^{1,2}\left[\right.$ Simon C. Hunter ${ }^{2} \cdot$ Susan Rasmussen ${ }^{2}$
}

Published online: 4 September 2019

(c) The Author(s) 2019

\begin{abstract}
The aim of the study was to test the relationship between experiences of being bullied, cyberbullied, and mental health difficulties, and whether these relationships are moderated by perceived social support and gender. Data were collected from 3737 year 8 pupils (aged 12 and 13 years; 50.1\% male) using an online questionnaire. Measures of bullying victimization, perceived social support, and mental health difficulties were included in the online questionnaire. Moderation analyses were conducted to test whether the relationships between being bullied, cyberbullied, and mental health difficulties were moderated by perceived social support and gender. Four models were estimated, each assessing a different source of perceived social support (from family, friends and peers, professional sources, and the perception of having no support). Results of these analyses indicated that across all four models being bullied was significantly associated with mental health difficulties, and being cyberbullied was only significantly associated with poorer mental health difficulties in girls in one of the models. The different sources of perceived social support did not moderate the relationship between experiences of being bullied or cyberbullied and mental health difficulties for either boys or girls. However, significant associations were found between a perceived lack of support, perceived social support from friends and family, and mental health difficulties in girls, but not in boys. The results contribute to a complex body of research findings exploring the role of perceived social support in the relationship between experiences of being bullied and mental health difficulties.
\end{abstract}

Keywords Bullying $\cdot$ Cyberbullying $\cdot$ Perceived social support $\cdot$ Mental health difficulties

\section{Introduction}

Being bullied is a frequent experience for many adolescents (Juvonen \& Graham, 2014), and one which can relate to mental health difficulties in both the short- and long-term (Ttofi, Farrington, Lösel, \& Loeber, 2011). Perceived social support is one factor which may buffer the relationship between experiences of being bullied and mental health difficulties, providing adolescents with resources to draw upon for support. A recent systematic review has highlighted gender differences in the buffering effect of perceived social support, alongside differences on the basis of the source of perceived social support, in the relationship between

Nathalie Noret

n.noret@yorksj.ac.uk

1 York St John University, Lord Mayors Walk, York YO31 7EX, UK

2 University of Strathclyde, Glasgow G1 1QE, UK experiences of being bullied and mental health difficulties (Noret, Hunter, \& Rasmussen, 2018). Therefore, the aim of this study is to examine the extent to which different sources of perceived social support moderate the relationship between experiences of being bullied, cyberbullied, and mental health difficulties.

Bullying is a distinct form of aggressive behavior which is experienced repeatedly, over time, and where there is an imbalance of power between those perpetrating the aggression and the recipient, for example on the basis of physical strength or popularity (Olweus, 1999; Whitney \& Smith, 1993). The behavior also includes an element of intentionality, defined as the intention on the part of the perpetrator to hurt the target (Olweus, 1978). Bullying can involve directly observable acts, such as verbal (e.g., name calling) or physical aggression (e.g., being hit, kicked, or punched) (Marini, Dane, Bosacki, \& YLS-CURA, 2006), and more indirect behaviors (e.g., being left out of a group, or being ignored) (Crick \& Grotpeter, 1995). Cyberbullying is defined as bullying which is perpetrated through electronic 
and communication tools (Campbell, 2005; Hinduja \& Patchin, 2008) and can involve both directly observable (e.g., mean and humiliating posts on social media sites) and more indirect behaviors (e.g., blocking someone from an online conversation) (Langos, 2012).

In their recent survey of 120,115 UK adolescents, Przybylski and Bowes (2017) found that $27 \%$ of their sample had experiences of being directly and indirectly bullied only. Less than $1 \%$ of their participants had experienced being cyberbullied only, and approximately $3 \%$ had experienced all three forms of aggression. Similar findings have been reported in a large-scale survey of 440,000 US students, where $17.3 \%$ of participants reported being verbally bullied, compared to $4.5 \%$ of participants who reported being cyberbullied (Olweus \& Limber, 2018). Such findings suggest that while many adolescents experience being cyberbullied, other forms of bullying are more commonly reported (Olweus, 2012). While experiences of being bullied and cyberbullied have often been studied separately, there have been calls for cyberbullying to be viewed as a form of bullying and one which should be studied as part of a broader 'bullying context' (Olweus \& Limber, 2018). Studying both experiences of being bullied and cyberbullied in parallel allows us to understand the unique and combined impact of these different bullying experiences (e.g., Gualdo, Hunter, Durkin, Arnaiz, \& Maquilón, 2015).

Adolescence is a time of substantial change in the peer group, involving a transition toward a greater importance of peer relationships and peer group status (Bukowski, Hoza, \& Boivin, 1993). Being bullied challenges these peer group goals as the aim of those perpetrating bullying is to demean and humiliate victims in front of the peer group, damaging social reputation and status (Juvonen \& Graham, 2014). A number of meta-analyses have demonstrated the relationship between being bullied and mental health difficulties, such as internalizing symptoms of depression and anxiety, and externalizing symptoms such as aggression (Reijntjes et al., 2011; Reijntjes, Kamphuis, Prinzie, \& Telch, 2010). In their recent review, Gini, Card, and Pozzoli (2018), found that both experiences of being bullied and being cyberbullied were independently associated with mental health difficulties. Such relationships have been found in both cross-sectional and longitudinal studies, suggesting both an immediate and long-term association between being bullied, cyberbullied, and mental health difficulties (Ttofi, Farrington, Lösel, \& Loeber, 2011). However, not all those who have been bullied develop mental health difficulties (Newman, Holden, \& Delville, 2005). The transactional model of stress (TMS) (Lazarus \& Folkman, 1984) offers a possible theoretical framework for examining individual differences in the relationship between victimization and negative outcomes (Noret et al., 2018; Raskauskas \& Huynh, 2015).
The TMS proposes that reactions to stressful situations, such as being bullied, are the product of a process of primary and secondary cognitive appraisal, and the coping strategy employed. Primary appraisals reflect an individual's evaluation of the importance of the event in the context of their own personal goals and beliefs, whereas secondary appraisals reflect an individual's evaluation of the resources they have available to manage the situation (Lazarus \& Folkman, 1984). Perceived social support is one form of secondary appraisal and reflects the extent to which individuals believe they are loved and valued and can depend on others for support when faced with stressful or challenging situations (Cobb, 1976; Lakey \& Cohen, 2000). The stress buffering hypothesis (Cohen \& Willis, 1985) suggests that perceived social support can moderate the relationship between a stressor and negative outcomes, where the relationship will be weaker in those with a high level of perceived support. Cohen and Willis (1985) proposed that this buffering role can function in two ways: It can reduce the perception of threat or risk of harm appraised in a given situation, or it can provide individuals with options to manage and cope with the stressor. Alternatively, the main effect model of perceived social support (Cohen, 2004; Cohen \& Willis, 1985) suggests that perceived social support can directly predict positive mental health, even in the absence of any stressful or challenging situations. The perception of having social support provides individuals with the feeling that they are supported and accepted, and have resources available to manage challenging situations (Cohen, 2004).

The perception of domain-specific social support reflects the perceived support available from specific individuals (Pierce, Sarason, \& Sarason, 1991). From a socio-ecological perspective, in early adolescence, domain-specific sources of support may reflect support from family, friends and peers, and teachers. Such individuals are all part of an adolescent's microsystem and are likely to have an important influence on adolescent development (Bokhorst, Sumter \& Westenberg, 2010; Pössel et al., 2018). While the importance of peer relationships increases in adolescence (Bukowski et al., 1993), family relationships continue to be an important form of social influence (Desjardins \& Leadbeater, 2011). Adolescents also spend a great deal of time at school in the presence of teachers and peers. As adolescents develop greater independence and autonomy, it may be that these sources of social support are evaluated as important for schoolrelated stressors as they offer the opportunity to seek support beyond the family (Yeung \& Leadbeater, 2010).

Understanding the social context in which bullying occurs, and the individual predictive relationships of different sources of perceived social support, is important to understand both the unique associations with psychological adjustment, and the development of prevention and intervention activities (Demaray \& Malecki, 2003; Pössel et al., 
2018). These different forms of domain-specific perceived social support have been examined within a bullying context. In their systematic review of this literature, Noret et al. (2018) highlighted that research to date has focused on the moderating (buffering) role of support from particular individuals, specifically parents, teachers, peers/classmates, and close friends.

Focusing specifically on perceived social support from adults, in a bullying context perceived social support from teachers and parents tend to be the sources of support most frequently examined. While perceived support from such adults has been found to be protective, gender differences in the literature have been reported. For example, a moderating role for perceived support from a teacher has been found in boys but not girls (Davidson \& Demaray, 2007), whereas Tanigawa, Furlong, Felix, and Sharkey (2011) found no moderating role for perceived teacher support. Similarly, regarding perceived support from parents/guardians, contradictory gender differences have been reported. Perceived social support from a parent/guardian has been found to moderate the relationship between being bullied and adjustment in girls but not in boys (Davidson \& Demaray, 2007), and separately in boys but not girls (Tanigawa, Furlong, Felix, \& Sharkey, 2011), whereas some report no moderating role for parental support (e.g., Cheng, Cheung, \& Cheung, 2008; Holt \& Espelage, 2007). The ages of participants across these studies spanned across late childhood and adolescence. As adolescents move toward greater independence, this may be reflected in a greater importance placed on other adults in their social network (e.g., teachers) and friends (Bokhorst et al., 2010; Helsen, Vollebergh $\&$ Meuus, 2000). Therefore, the different findings reported in these studies may reflect developmental differences in the importance of different forms of perceived support (Pössel et al., 2018; Noret et al., 2018). Despite the inconsistent findings, those studies reporting a buffering role for parent and/or teacher support found it to be protective, where the relationship between experiences of being bullied and mental health difficulties was weaker for those with greater perceived support in these domains.

In a bullying context, support from friends and peers is the most frequently studied form of domain-specific perceived support. Findings from these studies have also yielded inconsistent findings (Noret et al., 2018). Some studies have demonstrated a protective buffering role in boys but not girls (Cheng et al., 2008; Tanigawa et al., 2011), and some studies have demonstrated this finding in girls but not in boys (Lim et al., 2011). Others have reported that the relationship between experiences of being bullied and mental health difficulties is worse for those with perceived support from friends or peers (e.g., Holt \& Espelage, 2007). These inconsistent findings may reflect the different ways in which perceived social support has been measured, or whether the focus was on perceived social support from peers or from close/best friends (Chu et al., 2010; Rueger, Malecki, \& Demaray, 2010). Alternatively, these differences may be reflective of the changeable nature of peer relationships and friendships in adolescence (Gariépy, Honkaniemi, \& Quesnel-Vallée, 2016).

More recent research suggests that these different forms of domain-specific perceived social support can buffer the relationship between experiences of being cyberbullied and mental health difficulties. In their study of perceived support from family, defined as the number of family dinners, Elgar et al. (2014) found that such support moderated the relationship between experiences of being cyberbullied and mental health difficulties. The relationship was weaker in adolescents who reported a higher number of family dinners. Wright (2017) has also demonstrated the relationship longitudinally in her study of 131 pupils with developmental disorders: Perceived social support from parents and teachers moderated the relationship between experiences of being cyberbullied and depressive symptomology measured 1 year later. Such research supports a stress buffering role for perceived social support in the relationship between experiences of being bullied and mental health difficulties.

Although limited, there is evidence suggesting differences in the role of domain-specific forms of perceived social support in the relationship between different forms of bullying experiences and mental health difficulties (e.g., Yeung $\&$ Leadbeater, 2010). Different forms of perceived social support may be perceived as more or less helpful depending on the nature of the bullying experienced. Adolescents may be cautious about seeking help from the perceived support available for fear of any negative reactions, such as parents' overreaction (deLara, 2012), teachers not responding appropriately or their intervention making the situation worse (Bourke \& Burgman, 2010), or help-seeking resulting in further peer rejection (Cowie, 2011). The usefulness of perceived social support in managing experiences of being cyberbullied may also be evaluated differently to experiences of being bullied more generally, particularly with regard to perceived social support from adults. Adolescents may fear that parents will overreact which may result in a loss of access to technology and social media (Mishna, Saini, \& Solomon, 2009). Alternatively, adolescents may perceive that support from adults may be unhelpful due to their perception that adults have a limited understanding of cyberspace and technology (Machmutow, Perren, Sticca, \& Alsaker, 2012).

\section{The Current Study}

Research to date has reported mixed findings regarding the relationship between experiences of being bullied, cyberbullied, perceived social support, and mental 
health difficulties. Such research suggests that there may be gender differences in this relationship (e.g., Lim et al., 2011) and that perceived social support may not always be protective (e.g., Holt \& Espelage, 2007). Despite suggestions that experiences of being cyberbullied should be studied alongside experiences of other forms of bullying (Olweus \& Limber, 2018) and evidence that being cyberbullied is associated with mental health difficulties independently of other forms of bullying (Gini, Card, \& Pozzoli, 2018), much of the research exploring the role of perceived social support has tended to measure either experiences of being bullied or cyberbullied, and has tended to measure only one form of perceived support. Furthermore, no studies have examined the role of different forms of perceived social support in the relationship between experiences of being cyberbullied and mental health difficulties.

The current study will build upon previous research and address some of the limitations identified, to test for gender differences in the role of domain-specific forms of perceived social support in the relationship between both experiences of being bullied and cyberbullied, and mental health difficulties. Specifically, the following research questions will be addressed: (1) Is there a gender difference in the experience of being bullied, in perceived social support, and in symptoms of mental health difficulties? (2) Are experiences of being cyberbullied and being bullied significantly associated with mental health difficulties? (3) Does the perception of having no social support moderate the relationship between being bullied and cyberbullied and mental health difficulties? (4) Does perceived social support from family, peers, and/or professionals moderate the relationship between being bullied and mental health and being cyberbullied and mental health difficulties? (5) Does gender moderate the relationships between experiences of being bullied, cyberbullied, perceived social support, and mental health difficulties?

\section{Method}

\section{Design and Participants}

A cross-sectional survey design was employed. Participants were 3737 year 8 pupils, $50.1 \%$ were male $(N=1873), 48.4 \%$ were female $(N=1807)$, and $1.5 \%$ $(N=57)$ did not report their gender. All pupils were year 8 pupils (equivalent to 7 th grade in the US school system) and were aged 12 and 13 years. As year 8 pupils, participants were in their second year of secondary school education. Participants were recruited over three academic years (2012-2014) from 10 secondary schools within one local authority region in the North of England.

\section{Measures}

The current study is based on the secondary data analysis of data collected through a local education authority (LEA) project examining the experiences of being bullied and general well-being of children and young people in local primary (elementary schools in the USA) and secondary schools (junior high school in the USA). The project involved consultation with LEA representatives, head teachers, educational psychologists, and representatives from the police. The questionnaire examined general experiences at school, experiences of being bullied, bullying others, and witnessing bullying at school, alongside reports of current worries, concerns, perceived social support, and mental health difficulties. The questionnaire took pupils approximately $30 \mathrm{~min}$ to complete. Of interest to this study were participants' reports of being bullied, their perceived social support, and their responses to the measure of mental health difficulties.

\section{Experiences of Being Bullied}

Pupils were presented with the following definition: Being bullied means that you have been intentionally hurt (meaning someone did it on purpose) and that you were hurt by one person or a group of people more than once. The definition was developed in consultation with the LEA to reflect how bullying was discussed with pupils in the local schools. Pupils were then presented with a list of thirteen behaviors and asked to report on how often in the past month they had experienced the behaviors. These behaviors were based in part on the Olweus Bully/Victim Questionnaire (Solberg \& Olweus, 2003) and included the addition of items related to the experience of cyberbullying. The list included three examples of physical bullying (been hit or kicked or punched; threatened with being hurt; and been frightened by a look or stare), one item related to verbal bullying (been called names, or been insulted), three examples of relational bullying (been ignored by others; had rumors spread about you; and been left out of a group), five cyberbullying items (received nasty text messages; received nasty e-mails; been blocked from an online conversation; had something hurtful posted on a social networking site; and had someone posted an embarrassing photograph or video of you on a Web site), and an item relating to being bullied in other ways. Pupils were asked how often they had experienced each of the behaviors in the past month on a five-point Likert scale, ranging from This hasn't happened to me in the past month (1) to At least once a day (5). As the scale was designed for the 
purposes of the study, it was unclear how items would cluster together. Therefore, an exploratory factor analysis (maximum likelihood) using direct oblimin rotation was conducted using SPSS. The analysis yielded a two-factor model, identified through the scree plot and rotated component matrix, with items clustering around two factors: experiences of being bullied and experiences of being cyberbullied. The two factors accounted for $57.33 \%$ of the variance, with bullying accounting for $45.87 \%$ and cyberbullying accounting for a further $11.46 \%$. Both factors had eigenvalues greater than one: bullying $=5.51$ and cyberbullying $=1.38$. The internal reliability of both scales was good: for bullying $\alpha=.84$ and for cyberbullying $\alpha=.85$. Items were meaned to create scores ranging from 1 to 5 , with higher scores indicating more frequent experiences of being bullied.

\section{Perceived Social Support}

A measure of perceived social support was developed in collaboration with the LEA. The measure was similar to other categorical measures of perceived social support in that pupils were provided with a list of possible sources of support (e.g., Rigby \& Slee, 1999; Sarason, Levine, Basham, \& Sarason, 1983). But rather than asking participants about the amount of support available, the measure asked pupils whether they could or could not seek support from the different sources of support presented. Pupils were presented with the following instruction: If you were in trouble or were concerned about something who would you confide in (who would you talk to), please select all the answers that apply to you. Pupils were then presented with a list of 17 possible sources of support clustering around four domains, including having no one to talk to, sources of family support (parent or person who looks after me, brother or sister; aunt, uncle, or cousin, grandparents or grandparent), sources of friend/peer support (friend; boyfriend or girlfriend, older pupil), and sources of professional support (a teacher; non-teaching staff at school; school nurse; school counselor; chaplain; PSHE coordinator; youth worker; peer mentor). The question also included an other option; however, this was not included in the analysis.

For each item, pupils indicated whether they felt they could talk to each person (coded as yes $=1$ ), or they could not talk to that person $($ no $=0)$. For the purposes of this study, the individual sources of supported were grouped to represent sources of support from family, friends and peers, and professional support. Responses were coded as to whether participants did $(=1)$ or did not have access $(=0)$ to support from family, from teachers, and/or from professional sources. The item related to having no one to talk to was analyzed separately and coded differently. This item was coded as $1=$ having no one to talk to and $0=$ having someone to talk to.

\section{Mental Health Difficulties}

Mental health difficulties were measured using the short 12-item version of the General Health Questionnaire (GHQ12) (Goldberg \& Williams, 1988). Pupils were presented with a list of 12 statements reflecting different thoughts and feelings (e.g., lost much sleep over worry?) and were asked how often they felt that way in the past month. Responses to the 12 statements were rated on different four-point Likert scales, to capture the severity of distress (Tait, Hulse, \& Robertson, 2003). Item 1 was rated on a four-point scale from better than usual (1) to much less than usual (4), items 2 to 7 were rated on a four-point scale from not at all (1) to much more than usual (4), and items 8 to 12 were rated on a four-point scale from more so than usual (1) to much less than usual (4). Responses to items are then meaned to create a score from 1 to 4 , a lower score reflects a lower experience of mental health difficulties (and so better mental health), higher scores indicate a more frequent experience of mental health difficulties. The GHQ-12 has been found to have good internal reliability and has previously been used with adolescent samples to measure mental health difficulties (Baksheev, Robinson, Cosgrave, Baker, \& Yung, 2011). In the current study, the internal reliability of the scale was good (Cronbach's $\alpha=.91$ ).

\section{Procedure}

The study was approved by the university's research ethics committee. The survey was administered online using the SurveyMonkey online survey tool. Schools were recruited with support from the LEA during an annual briefing session. All secondary schools in the area $(N=10)$ participated in the study annually over the 3-year period, with data being collected from a different cohort of year 8 pupils every year. To ensure consistency in the administration of the survey, schools were provided with a list of standardized instructions and a presentation file. Schools then administered the survey to their pupils in a designated lesson, in examination conditions. Data collection occurred at the same point every year, in the summer term (June/July).

\section{Data Analysis}

Moderation analyses were conducted using Mplus (version 7.31 MAC). Results were downloaded from the SurveyMonkey tool, and the GHQ, bullying, and cyberbullying scales were calculated using SPSS (version 24). Continuous predictors were mean centered before interaction terms 
were created. Moderation analyses were conducted using maximum likelihood with robust standard errors estimation (MLR) to account for the categorical nature of the moderators (the sources of perceived social support and gender). The analyses were conducted using full information maximum likelihood (FIML) to account for missing data.

An initial model was calculated including the main effects of experiences of being bullied, being cyberbullied, all sources of perceived social support, and where gender and all sources of perceived social support (except having no one to talk to) were entered as moderators. Variance inflation factors (VIFs) and tolerance statistics were calculated to identify any issues with multi-collinearity. In this initial model, the levels of multi-collinearity exceeded acceptable limits (VIF > 5) (Akinwande, Dikko, \& Samson, 2015), with VIF values ranging from 7 to 12 . To address this, four separate models were calculated, one for each source of support; see Fig. 1. The measure of social support was entered as a moderator in each model, and the multi-groups method was used to test for the moderating role of gender. The Satorra-Bentler rescaled Chi-square test was used to compare the models for boys and girls, and individual $z$ tests were also used to test for gender differences in unstandardized regression coefficients (Paternoster, Brame, Mazerolle, \& Piquero, 1998).

When reporting the results of the moderation analysis, both unstandardized and standardized path coefficients are presented. For continuous predictors (experiences of being bullied and cyberbullied), standardized paths are calculated based on the standard deviations of both the predictor $(x)$ and outcome variables (y) (StdYX in Mplus) (Muthén \& Muthén, 2017). For categorical predictors (sources of social support), standardized paths are calculated on the basis of the standard deviation of the outcome variable and are interpreted as a standard deviation change in the outcome variable as the predictor variable changes from 0 to 1 ( $\mathrm{StdY}$ in Mplus) (Muthén \& Muthén, 2017).

\section{Results}

\section{Is There a Gender Difference in the Experience of Being Bullied, in Perceived Social Support and Symptoms of Mental Health Difficulties?}

\section{Experiences of Being Bullied, Cyberbullied, and Mental Health Difficulties}

As shown in Table 1, participants reported experiencing bullying more often than cyberbullying. There were significant correlations between being bullied and being cyberbullied. Significant correlations were also found between both being bullied and being cyberbullied and mental health difficulties.

Table 2 shows the descriptive statistics and correlations, presented separately for boys and girls. Girls reported experiencing being bullied and cyberbullied more than boys. Scores of mental health difficulties were also higher in girls than boys. Significant positive correlations between experiences of being bullied, cyberbullied, and mental health difficulties were found in both boys and girls. Gender differences in mental health difficulties, experiences of being bullied and being cyberbullied scores were analyzed using independent $t$ tests. Significant differences and small effects in mental health difficulties and experiences of being cyberbullied scores were found. In

Table 1 Descriptive statistics and correlations for bullying, cyberbullying, and mental health difficulties

\begin{tabular}{llll}
\hline & 1 & 2 & $M(\mathrm{SD})$ \\
\hline 1. Bullying & - & - & $1.60(.79)$ \\
2. Cyberbullying & $.60 * * *$ & - & $1.18(.50)$ \\
3. Mental health difficulties & $.39 * * *$ & $30^{* * *}$ & $1.74(.54)$ \\
\hline$* * * p<.001$ & & &
\end{tabular}

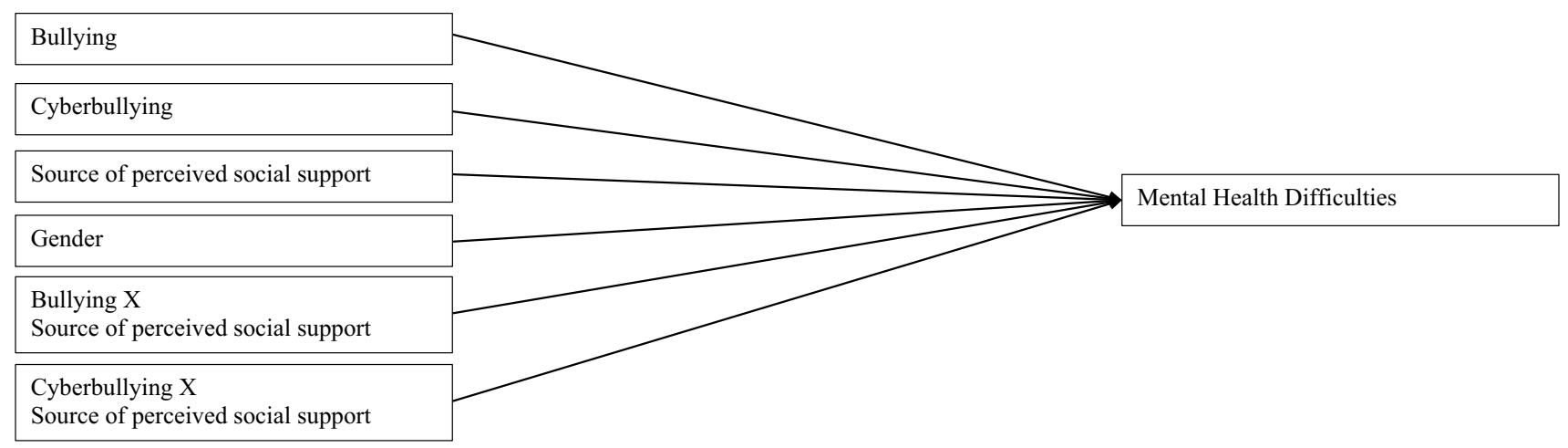

Fig. 1 Example model. Note: The multi-groups method was also used to test whether gender moderated the relationships presented in this model 
Table 2 Descriptive statistics and correlations shown by gender

\begin{tabular}{lllllll}
\hline & 1 & 2 & 3 & \multicolumn{2}{l}{$M(\mathrm{SD})$} & \multirow{2}{*}{$t$} \\
\cline { 5 - 6 } & & & & Boys & Girls & \\
\hline 1. Bullying & - & $.55^{* * *}$ & $.35^{* * *}$ & $1.59(.79)$ & $1.61(.78)$ & $0.47, p=0.64$ \\
2. Cyberbullying & $.65^{* * *}$ & - & $.23^{* * *}$ & $1.14(.46)$ & $1.22(.53)$ & $4.15^{* * *}, d=0.16$ \\
3. Mental health difficulties & $.45^{* * *}$ & $.35^{* * *}$ & - & $1.63(.49)$ & $1.84(.58)$ & $11.30^{* * *}, d=0.20$ \\
\hline
\end{tabular}

$* * * p<.001$, correlations for boys are shown above the diagonal and for girls below both cases, girls reported higher scores than boys. No significant differences were found in scores of being bullied.

\section{Perceived Social Support}

The sources of support participants reported having available are shown in Table 3. Overall, $11.6 \%$ of the sample reported having no one to talk to. Support from family was more frequently reported than professional support or support from friends/peers. Chi-square analyses were used to test the association between gender and the different sources or perceived social support. There was a significant association, and small effect, between gender and having no one to talk to, a higher proportion of boys reported having no one to talk to. Significant associations and small effects were also found between gender and talking to family, and between gender and talking to friends and peers. A higher proportion of girls reported being able to talk to family or friends/ peers. No significant association was found between gender and professional support. The proportion of boys and girls who reported being able to access professional support was approximately equal.

\section{Are Experiences of Being Cyberbullied and Being Bullied Significantly Associated with Mental Health Difficulties?}

The four models accounted for between 24 and $25 \%$ of the variance in mental health difficulties $\left(R^{2}=.24\right.$ to .25$)$ for girls, and for boys between 11 and $12 \%$ of the variance $\left(R^{2}=.11\right.$ to .12). Across all four models, for both boys and girls, being bullied was significantly associated with mental health difficulties. Being cyberbullied was significantly associated with mental health difficulties for girls in only one model (model 4: assessing perceived support from professional sources).

\section{Does Perceived Social Support Moderate the Relationship Between Experiences of Being Bullied and Mental Health and Between Being Cyberbullied and Mental Health Difficulties?}

As shown in Table 4, across all four models no source of support moderated the relationship between experiences of being bullied or cyberbullied and mental health difficulties in either boys or girls.

\section{Does Gender Moderate the Relationships Between Experiences of Being Bullied, Being Cyberbullied, Perceived Social Support and Mental Health Difficulties?}

The moderating role of gender was examined using the multi-groups method of testing for moderation, using Satorra-Bentler tests. Gender moderated the relationships in the no social support model, $\mathrm{SB} \chi^{2}(d f=5)=20.37$, $p=.001$. A significant gender difference was found in the path between having no one to talk to and mental health difficulties, $Z=-2.33$. Having no one to talk to was significantly associated with mental health difficulties in girls ( $b=.16)$ but not in boys $(b=.004)$. Gender was also found to moderate associations in the family support model, $\mathrm{SB} \chi^{2}$ $(d f=5)=13.93, p=.020$. A significant gender difference was found in the association between perceived support from family and mental health difficulties; $Z=2.00$, this source of support was significantly associated with fewer mental health difficulties in girls $(b=-.15)$ but not in boys $(b=-.05)$. Gender significantly moderated the relationships in the friend support model, $\mathrm{SB} \chi^{2}(d f=5)=11.65, p=.040$.
Table 3 Number (and percentage) of participants reporting who they would talk to if they were worried or concerned about something

\begin{tabular}{lrrrrr}
\hline & \multicolumn{1}{l}{ Total } & \multicolumn{1}{l}{ Boys } & \multicolumn{1}{c}{ Girls } & \multicolumn{1}{c}{$\chi^{2}(1)$} & $\varphi$ \\
\hline No one & $435(11.6 \%)$ & $295(18.6 \%)$ & $137(7.6 \%)$ & $65.90^{* * *}$ & .10 \\
Support from family & $2338(62.6 \%)$ & $1134(60.5 \%)$ & $1197(66.2 \%)$ & $7.92^{* *}$ & .05 \\
Support from friends/peers & $1752(46.9 \%)$ & $663(35.4 \%)$ & $1084(60.0 \%)$ & $232.20^{* * *}$ & .20 \\
Professional support & $766(20.5 \%)$ & $398(21.2 \%)$ & $363(20.1 \%)$ & 1.87 & N/A \\
\hline
\end{tabular}

$* * p<.01, * * * p<.001$ 
Table 4 Moderation analyses: the relationships between bullying, cyberbullying, perceived social support, and mental health difficulties

\begin{tabular}{|c|c|c|c|c|c|c|c|c|c|c|c|c|c|}
\hline & \multicolumn{6}{|c|}{ Males } & \multicolumn{6}{|c|}{ Females } & \multirow[t]{3}{*}{$Z$} \\
\hline & \multirow[t]{2}{*}{$R^{2}$} & \multicolumn{2}{|c|}{$\begin{array}{l}\text { Unstand- } \\
\text { ardized }\end{array}$} & \multicolumn{3}{|c|}{ Standardized } & \multirow[t]{2}{*}{$R^{2}$} & \multicolumn{2}{|c|}{$\begin{array}{l}\text { Unstandard- } \\
\text { ized }\end{array}$} & \multicolumn{3}{|c|}{ Standardized } & \\
\hline & & $b$ & $\mathrm{SEb}$ & $\beta$ & SE & $95 \% \mathrm{CI}$ & & $b$ & $\mathrm{SEb}$ & $\beta$ & SE & $95 \% \mathrm{CI}$ & \\
\hline Model 1: No social support & .12 & & & & & & .25 & & & & & & \\
\hline Bullying & & $.22 *$ & .03 & $.34 *$ & .04 & $.26: .41$ & & $.30 *$ & .04 & $.42 *$ & .05 & $.33: .52$ & 1.60 \\
\hline Cyberbullying & & .06 & .08 & .06 & .07 & $-.08: .20$ & & .05 & .07 & .05 & .07 & $-.08: .17$ & 0.09 \\
\hline Social support & & .004 & 4.03 & .003 & .03 & $-.05: .05$ & & $-.16^{*}$ & .06 & $.08 *$ & .03 & $.02: .14$ & $-2.33^{*}$ \\
\hline Bullying $\times$ Social support & & -.11 & .07 & -.08 & .05 & $-.18: .02$ & & .04 & .11 & -.02 & .06 & $-.14: .09$ & -0.54 \\
\hline Cyberbullying $\times$ Social support & & .02 & .18 & .01 & .09 & $-.16: .19$ & & .14 & .15 & .09 & .06 & $-.03: .20$ & -0.51 \\
\hline Model 2: Perceived support from family & .12 & & & & & & .25 & & & & & & \\
\hline Bullying & & $.13^{*}$ & k.05 & $.20 *$ & .07 & $.07: 34$ & & $.27 *$ & .07 & $.37 *$ & .09 & $.19: .55$ & -1.63 \\
\hline Cyberbullying & & .13 & .12 & .11 & .10 & $-.09: .32$ & & .17 & .12 & .16 & .11 & $-.05: .45$ & -0.24 \\
\hline Family support & & -.05 & .03 & -.04 & .03 & $-.09: .01$ & & $-.15^{*}$ & .04 & $-.11 *$ & .03 & $-.16:-.06$ & $2.00 *$ \\
\hline Bullying $\times$ Family support & & .09 & .06 & .11 & .07 & $-.02: .24$ & & .04 & .08 & .05 & .09 & $-.12: .22$ & 0.83 \\
\hline Cyberbullying $\times$ Family support & & -.13 & .15 & -.08 & .09 & $-.25: .10$ & & -.14 & .14 & -.10 & .10 & $-.29: .10$ & 0.05 \\
\hline Model 3: Perceived support from friends/peers & .11 & & & & & & .24 & & & & & & \\
\hline Bullying & & $.20 *$ & .04 & $.30 *$ & .05 & $.20: .40$ & & $.28 *$ & .07 & $.40 *$ & .09 & $.21: .58$ & -0.99 \\
\hline Cyberbullying & & .08 & .11 & .07 & .10 & $-.13: .27$ & & .14 & .13 & .14 & .13 & $-.11: .39$ & -0.35 \\
\hline Friend/peer support & & .04 & .02 & .04 & .02 & $-.01: .08$ & & $.07 *$ & .03 & $.06^{*}$ & .03 & $.01: 11$ & -0.83 \\
\hline Bullying $\times$ Friend/peer support & & .01 & .05 & .01 & .05 & $-.09: .11$ & & .03 & .08 & .04 & .08 & $-.13: .20$ & -0.21 \\
\hline Cyberbullying $\times$ Friend/peer support & & -.09 & .15 & -.05 & .09 & $-.23: .13$ & & -.08 & .15 & -.06 & .11 & $-.28: .16$ & -0.05 \\
\hline Model 4: Perceived professional support & .11 & & & & & & .24 & & & & & & \\
\hline Bullying & & $.21 *$ & .03 & $.32 *$ & .05 & $.23: .40$ & & $.30 *$ & .04 & $.42 *$ & .06 & $.31: .52$ & -1.80 \\
\hline Cyberbullying & & .11 & .08 & .10 & .07 & $-.05: .24$ & & $.14 *$ & .07 & $.13^{*}$ & .07 & $.004: .30$ & -0.28 \\
\hline Professional support & & -.01 & .03 & -.01 & .02 & $-.06: .03$ & & .01 & .03 & .01 & .03 & $-.04: .06$ & -0.47 \\
\hline Bullying $\times$ Professional support & & -.04 & .06 & -.03 & .05 & $-.12: .06$ & & .02 & .08 & .02 & .06 & $-.10: .17$ & -0.60 \\
\hline Cyberbullying $\times$ Professional support & & -.11 & .14 & -.06 & .08 & $-.22: .10$ & & -.15 & .15 & -.07 & .08 & $-.23: .13$ & 0.19 \\
\hline
\end{tabular}

The $z$ scores reported in the table represent gender differences in the unstandardized betas

Model 1: No perceived social support is coded as $1=$ having no one to talk to and $0=$ having someone to talk to

Models 2-4:1 =has support in that domain and $0=$ does not have support in that domain

Higher mental health scores represent more mental health difficulties, and lower scores represent better mental health

$* p<.05$

The association between being able to talk to friends/peers was significantly associated with mental health difficulties in girls $(b=.07)$ but not in boys $(b=.04)$; however, no significant difference in the path between perceived support from friends/peers and mental health difficulties $(Z=-.83)$, or in any of the other paths was found. Gender did not moderate the relationships across variables in the professional support model, $\mathrm{SB} \chi^{2}(d f=5)=17.46, p=.071$.

\section{Discussion}

The aim of the current study was to examine the role of perceived social support in the relationship between experiences of being bullied, cyberbullied, and mental health difficulties, and whether this was moderated by gender. Being bullied was significantly associated with mental health difficulties across all four models. Of the four models, experiences of being cyberbullied were only directly associated with mental health difficulties in the model assessing perceived support from professional sources. Perceived social support from friends/peers and parents and the perception of having no one to talk to were associated with mental health difficulties in girls but not in boys. No source of perceived social support moderated the relationships between being bullied or being cyberbullied and mental health difficulties, in either girls or boys.

Consistent with previous research (e.g., Przybylski \& Bowes, 2017), experiences of being bullied were more frequently reported than experiences of being cyberbullied by both boys and girls. The prevalence of being bullied was similar in boys and girls; however, reports of being 
cyberbullied were significantly higher in girls. This finding is consistent with some previous studies (e.g., Rivers \& Noret, 2010; Study 1 in Smith et al., 2008); however, gender differences in experiences of being cyberbullied are inconsistent in the research literature (Tokunaga, 2010). The gender difference in experiences of being cyberbullied identified in the current study may be due to different usage in early adolescence. Gender differences have been reported in a number of studies, where boys typically report engaging in more gaming activities, and girls report greater use of social media (Houghton et al., 2015; Rosenberg et al., 2018). The measure used in the current study focuses on cyberbullying which occurred through social media (e.g., being left out of an online conversation or having a humiliating/embarrassing picture taken) or through mobile phone (e.g., nasty text messages) but did not include any reference to bullying which occurs through online games. Recent research has identified this as a common experience in online games, and more frequently experienced by boys (e.g., Lee \& Shin, 2017). Future research should include online gaming in any measure of cyberbullying.

Across all models, being bullied was associated with mental health difficulties for both boys and girls. The transactional model of stress (Lazarus \& Folkman, 1984) suggests that for an experience to be deemed stressful and lead to negative outcomes, it must first challenge particular goals held by the individual. Developing close and intimate friendships is a major developmental goal in early adolescence (Berndt, 1982). Experiences of being bullied challenge such goals, by damaging friendships and social relationships (Juvonen \& Graham, 2014) which can subsequently lead to mental health difficulties. Unlike other research (e.g., Gini, Card, \& Pozzoli, 2018), no independent association was found between experiences of being cyberbullied and mental health difficulties, except in model four (the professional support model). Some forms of cyberbullying are very public, and this visibility may result in others intervening and supporting the victim (Slonje, Smith, \& Frisén, 2017), providing strategies for coping with the cyberbullying before it begins to impact mental health difficulties. In a professional context, it may be that professionals working with young adolescents may not be witness to the experiences or may not be able to effectively stop cyberbullying, which may lead to a continuation of the behavior and subsequent impact on mental health difficulties. This different pattern of associations between bullying, cyberbullying, and mental health difficulties reported in this study highlights the importance of studying experiences of being cyberbullied in a broader bullying context rather than in isolation (Olweus and Limber, 2018).

The findings of this study also highlight gender differences in adolescents' perceptions of available support. More boys reported having no one to talk to about their worries and concerns compared to girls. Consistent with previous research (e.g., Furman \& Buhrmester, 1992), girls were significantly more likely to report perceived support from friends/peers. Girls were also more likely to report support from parents and teachers. There was no significant gender difference in the perception of available professional support. The gender differences in the perception of available suppor, may reflect the nature of girls' social relationships in early adolescence. Compared to boys, girls are more likely to seek out intimacy and closeness in relationships, and are more likely to spend time developing such relationships (Rueger et al., 2010). Such gender differences in the development of social relationships in early adolescence may explain the difference in perceptions of available support reported in this study.

Gender differences were also found in the relationship between perceived social support and mental health difficulties. None of the sources of support were associated with mental health difficulties for boys. The gender differences in the perception of available support may reflect gender differences in the importance of social relationships in early adolescence or gender differences in coping styles (Rueger, Malexki, \& Demaray, 2010). In girls, the perception of having no one to talk to and the perception of support from friends/peers were both significantly associated with mental health difficulties, while the perceived social support from parents was significantly associated with fewer mental health difficulties and therefore better mental health. Similar to more global measures of perceived social support, the perception of having no one to talk to may result in the perception of not being valued or supported, or isolated and vulnerable which may directly impact mental health difficulties (Stice, Ragan, \& Randall, 2004). The different pattern of associations for perceived support from family, and perceived support from friends and peers, reflects findings from the broader literature on the relationship between perceived social support and depression (e.g., Stice, Ragan, \& Randall, 2004). The perception of support from parents and family more broadly may be more valuable as such support is more consistent. Parents and older family members may be better equipped to provide more valuable support and better guidance based on their life experience (Stice, Ragan, $\&$ Randall, 2004).

From a TMS perspective, as a form of secondary appraisal, perceived support from family may be evaluated as more important and useful as a reflection of the better guidance and support previously received. The association between perceived support from friends/peers and mental health difficulties may reflect the instability and changeable nature of the peer group, particularly in early adolescence (Stice, Ragan, \& Randall, 2004). This finding may reflect the evaluation of previous support sought from friends or the broader peer group. It may be that the support has not been 
helpful in the past (Hodges, Boivin, Vitaro, \& Bukowski, 1999 ), or that friends or peers have minimized the experiences (Camara, Bacigalupe, \& Padilla, 2017). Alternatively, if adolescents repeatedly seek support from friends/ peers this may result in support erosion (Slavin \& Rainer, 1990), or rejection from the peer group (Rueger, Malecki, Pyun, Aycock, \& Coyle, 2016). Understanding changes in the perception of available social support in relation to peer relationships is needed to better understand the relationship between this form of perceived social support and mental health difficulties.

Although perceived social support was associated with mental health difficulties in girls, it did not moderate the relationship between experiences of being bullied or cyberbullied and mental health difficulties, in either boys or girls. Therefore, the results of all four models lend support to the main effect model of perceived social support (Cohen, 2004) rather than the stress buffering hypothesis (Cohen \& Willis, 1985). A similar finding was reported by Rigby (2000), who suggested that while perceived social support did not moderate the relationship between victimization and mental health difficulties, it may be that a mediation model may offer a better explanation of the relationship. Being bullied is a unique stressor, in that the aim of this behavior is to damage social relationships and reputation (Juvonen \& Graham, 2014). Over time, as experiences of being bullied continue, it may be that social relationships are damaged, leaving those being victimized to feel isolated or struggle to develop social relationships (Rigby, 2000). Future longitudinal research is required to better understand the relationship between being bullied, perceived social support, and mental health difficulties to examine how continued experiences of being bullied damage peer networks and the perception of available support.

\section{Limitations and Future Directions}

The findings of this study contribute to a complex and inconsistent body of research findings examining the role of perceived social support in the relationship between experiences of being bullied and mental health difficulties. A strength of our study is that it investigated both experiences of being bullied and cyberbullied and the role of a number of different sources of perceived social support, in a large representative sample of 13- and 14-year-olds. This approach to measurement enabled us to identify different associations between different forms of bullying, and different forms of perceived social support.

The data were, however, collected using self-reported measures, which can be challenging for both bullying victimization and perceived social support. Identifying the prevalence of being bullied can vary due to methodological inconsistencies related to the way in which respondents are asked about their experiences. Reports of having experienced being bullied can vary due to the time frame provided and whether a definitional or behavioral approach has been taken (Olweus \& Limber, 2018; Volk, Veenstra, \& Espelage, 2017). In an attempt to manage these challenges, pupils were provided with a definition that was already used with pupils in schools in the LEA and also provided with a list of behaviors, to address the limitations associated with single item questions on bullying. However, the data collection was dependent on self-report, which may be affected by social desirability (Solberg \& Olweus, 2003). As such, future research could consider employing the use of peer or teacher nominations to supplement the self-reported data (Solberg \& Olweus, 2003).

Similarly, the challenges associated with measuring perceived social support are well documented and may explain the inconsistencies in research findings (Rueger, Malecki \& Demaray, 2010). In the current study, we measured perceived social support by focusing on who participants could talk to if they were worried or concerned about something. This approach enabled us to capture different sources of perceived social support available, but not the depth and nature of that support. Future research could consider the use of a more detailed measure of perceived social support to capture the nature of the perceived social support, for example the child and adolescent social support scale (Malecki \& Demaray, 2002).

The current study also relies on cross-sectional data, thereby limiting our ability to infer causal relationships between experiences of being bullied, perceived social support, and mental health difficulties. As discussed, further research is required to examine longitudinal relationships between being bullied, perceived social support, and mental health difficulties. Such research would enable us to examine any possible bidirectional relationships between being bullied and perceived social support, for example whether those with a reduced level of perceived social support are more at risk of being bullied, or how the continuation of being bullied may result in a reduction in the perception of available social support.

\section{Implications for Practice}

The findings of this study have important implications for professionals working with adolescents in school. When designing intervention and preventative programmes, the findings of the current study highlight the importance of capturing both bullying and cyberbullying in anti-bullying activities. The current study also highlights gender differences in the perception of social support and in the association between perceived social support and mental health difficulties in early adolescence. Our results highlight that perceived social support from friends and peers may not 
always be beneficial for girls. Encouraging those being bullied to seek help and enact upon available social forms the basis of a number of anti-bullying initiatives (Demaray \& Malecki, 2006). Future interventions could also consider working with the school community to raise awareness of how best to support those being bullied.

\section{Conclusion}

The results highlight different associations between bullying, cyberbullying, and mental health difficulties. These different relationships highlight the importance of studying both behaviors, rather than each in isolation. In addition, the gender differences in perceived social support, and the association with mental health difficulties, contribute to a complex body of the literature on the relationship between bullying, perceived social support and mental health difficulties. Such gender differences may have implications for the effectiveness of any interventions based on social support. Consistent with some previous research, this study highlights that perceived support from friends and peers may not always be protective, particularly for girls. Therefore, further research examining the longitudinal relationship between experiences of being bullied, peer relationships, and perceived social support is required to better inform intervention work.

Open Access This article is distributed under the terms of the Creative Commons Attribution 4.0 International License (http://creativeco mmons.org/licenses/by/4.0/), which permits unrestricted use, distribution, and reproduction in any medium, provided you give appropriate credit to the original author(s) and the source, provide a link to the Creative Commons license, and indicate if changes were made.

\section{References}

Akinwande, M. O., Dikko, H. G., \& Samson, A. (2015). Variance inflation factor: As a condition for the inclusion of suppressor variable(s) in regression analysis. Open Journal of Statistics, 5(7), 754-767. https://doi.org/10.4236/ojs.2015.57075.

Baksheev, G. N., Robinson, J., Cosgrave, E. M., Baker, K., \& Yung, A. R. (2011). Validity of the 12-item General Health Questionnaire (GHQ-12) in detecting depressive and anxiety disorders among high school students. Psychiatry Research, 187(1), 291-296. https ://doi.org/10.1016/j.psychres.2010.10.010.

Berndt, T. J. (1982). The features and effects of friendship in early adolescence. Child Development, 53, 1447-1460.

Bokhorst, C. L., Sumter, S. R., \& Westenberg, P. M. (2010). Social support from parents, friends, classmates, and teachers in children and adolescents aged 9 to 18 years: Who is perceived as most supportive? Social Development, 19(2), 417-426. https://doi.org/10. 1111/j.1467-9507.2009.00540.x.

Bourke, S., \& Burgman, I. (2010). Coping with bullying in Australian schools: How children with disabilities experience support from friends, parents and teachers. Disability \& Society, 25(3), 359-371. https://doi.org/10.1080/09687591003701264.

Bukowski, W. M., Hoza, B., \& Boivin, M. (1993). Popularity, friendship, and emotional adjustment during early adolescence. New
Directions for Child and Adolescent Development, 1993(60), 23-37. https://doi.org/10.1002/cd.23219936004.

Camara, M., Bacigalupe, G., \& Padilla, P. (2017). The role of social support in adolescents: Are you helping me or stressing me out? International Journal of Adolescence and Youth, 22(2), 123-136. https://doi.org/10.1080/02673843.2013.875480.

Campbell, M. A. (2005). Cyber bullying: An old problem in a new guise? Journal of Psychologists and Counsellors in Schools, 15(1), 68-76. https://doi.org/10.1375/ajgc.15.1.68.

Cheng, S. T., Cheung, K. C. C., \& Cheung, C. K. (2008). Peer victimization and depression among Hong-Kong adolescents. Journal of Clinical Psychology, 64(4), 766-776. https://doi. org/10.1002/jclp.20489.

Chu, P. S., Saucier, D. A., \& Hafner, E. (2010). Meta-analysis of the relationships between social support and well-being in children and adolescents. Journal of Social and Clinical Psychology, 29(6), 624-645. https://doi.org/10.1521/jscp.2010.29.6.624.

Cobb, S. (1976). Social support as a moderator of life stress. Psychosomatic Medicine, 38, 200-314.

Cohen, S. (2004). Social relationships and health. American Psychologist, 59, 676-684. https://doi. org/10.1037/0003-066X.59.8.676.

Cohen, S., \& Willis, T. A. (1985). Stress, social support, and the buffering hypothesis. Psychological Bulletin, 98(2), 310-357. https:// doi.org/10.1037/0033-2909.98.2.310.

Cowie, H. (2011). Peer support as an intervention to counteract school bullying: Listen to the children. Children and Society, 25(4), 287 292. https://doi.org/10.1111/j.1099-0860.2011.00375.x.

Crick, N. R., \& Grotpeter, J. K. (1995). Relational aggression, gender, and social-psychological adjustment. Child Development, 66(3), 710-722. https://doi.org/10.2307/1131945.

Davidson, L. M., \& Demaray, M. K. (2007). Social support as a moderator between victimization and internalizing-externalizing distress from bullying. School Psychology Review, 36(3), 383-405.

DeLara, E. W. (2012). Why adolescents don't disclose incidents of bullying and harassment. Journal of School Violence, 11(4), 288305. https://doi.org/10.1080/15388220.2012.705931.

Demaray, M. K., \& Malecki, C. K. (2003). Perceptions of the frequency and importance of social support by students classified as victims, bullies, and bully/victims in an urban middle school. School Psychology Review, 32(3), 471-490.

Demaray, M. K., \& Malecki, C. K. (2006). A review of the use of social support in anti-bullying programs. Journal of School Violence, 5(3), 51-70. https://doi.org/10.1300/J202v05n03_05.

Desjardins, T. L., \& Leadbeater, B. J. (2011). Relational victimization and depressive symptoms in adolescence: Moderating effects of mother, father, and peer emotional support. Journal of Youth and Adolescence, 40(5), 531-544. https://doi.org/10.1007/s1096 4-010-9562-1.

Elgar, F. J., Napoletano, A., Saul, G., Dirks, M. A., Craig, W., Poteat, V. P., et al. (2014). Cyberbullying victimization and mental health in adolescents and the moderating role of family dinners. JAMA Pediatrics, 168(11), 1015-1022. https://doi.org/10.1001/jamap ediatrics.2014.1223.

Furman, W., \& Buhrmester, D. (1992). Age and sex differences in perceptions of networks of personal relationships. Child Development, 63, 103-115. https://doi.org/10.2307/1130905.

Gariépy, G., Honkaniemi, H., \& Quesnel-Vallée, A. (2016). Social support and protection from depression: Systematic review of current findings in Western countries. The British Journal of Psychiatry, 209(4), 284-293. https://doi.org/10.1192/bjp.bp.115.169094.

Gini, G., Card, N. A., \& Pozzoli, T. (2018). A meta-analysis of the differential relations of traditional and cyber-victimization with internalizing problems. Aggressive Behavior, 44(2), 185-198. https://doi.org/10.1002/ab.21742. 
Goldberg, D. P., \& Williams, P. (1988). The user's guide to the general health questionnaire. Windsor: NFER-Nelson.

Gualdo, A. M. G., Hunter, S. C., Durkin, K., Arnaiz, P., \& Maquilón, J. J. (2015). The emotional impact of cyberbullying: Differences in perceptions and experiences as a function of role. Computers \& Education, 82, 228-235. https://doi.org/10.1016/j.compe du.2014.11.013.

Helsen, M., Vollebergh, W., \& Meeus, W. (2000). Social support from parents and friends and emotional problems in adolescence. Journal of Youth and Adolescence, 29(3), 319-335. https://doi. org/10.1023/A:1005147708827.

Hinduja, S., \& Patchin, J. W. (2008). Cyberbullying: An exploratory analysis of factors related to offending and victimization. Deviant Behavior, 29(2), 129-156. https://doi.org/10.1080/0163962070 1457816.

Hodges, E. V. E., Boivin, M., Vitaro, F., \& Bukowski, W. M. (1999). The power of friendship: Protection against an escalating cycle of peer victimization. Developmental Psychology, 35(1), 94-101. https://doi.org/10.1037/0012-1649.35.1.94.

Holt, M. K., \& Espelage, D. L. (2007). Perceived social support among bullies, victims, and bully-victims. Journal of Youth and Adolescence, 36(8), 984-994. https://doi.org/10.1007/s1096 4-006-9153-3.

Houghton, S., Hunter, S. C., Rosenberg, M., Wood, L., Zadow, C., Martin, K., et al. (2015). Virtually impossible: Limiting Australian children and adolescents daily screen based media use. BMC Public Health, 15(1), 5-16. https://doi.org/10.1186/1471-2458-15-5.

Juvonen, J., \& Graham, S. (2014). Bullying in schools: The power of bullies and the plight of victims. Annual Review of Psychology, 65, 159-185. https://doi.org/10.1146/annurev-psych-01021 3-115030.

Lakey, B., \& Cohen, S. (2000). Social support theory and selecting measures of social support. In S. Cohen, L. U. Gordon, \& B. H. Gottlieb (Eds.), Social support measurement and interventions: A guide for health and social scientists (pp. 29-52). New York, NY: Oxford University Press.

Langos, C. (2012). Cyberbullying: The challenge to define. Cyberpsychology, Behavior, and Social Networking, 15(6), 285-289. https ://doi.org/10.1089/cyber.2011.0588.

Lazarus, R. S., \& Folkman, S. (1984). Stress, appraisal, and coping. New York: Springer.

Lee, C., \& Shin, N. (2017). Prevalence of cyberbullying and predictors of cyberbullying perpetration among Korean adolescents. Computers in Human Behavior, 68, 352-358. https://doi.org/10.1016/j. chb.2016.11.047.

Lim, C. S., Graziano, P. A., Janicke, D. M., Gray, W. N., Ingerski, L. M., \& Silverstein, J. H. (2011). Peer victimization and depressive symptoms in obese youth: The role of perceived social support. Children's Health Care, 40(1), 1-15. https://doi. org/10.1080/02739615.2011.537929.

Machmutow, K., Perren, S., Sticca, F., \& Alsaker, F. D. (2012). Peer victimisation and depressive symptoms: Can specific coping strategies buffer the negative impact of cybervictimisation? Emotional and Behavioural Difficulties, 17(3-4), 403-420. https://doi. org/10.1080/13632752.2012.704310.

Malecki, C. K., \& Demaray, M. K. (2002). Measuring perceived social support: Development of the child and adolescent social support scale (CASSS). Psychology in the Schools, 39(1), 1-18. https:// doi.org/10.1002/pits.10004.

Marini, Z. A., Dane, A. V., Bosacki, S. L., \& Cura, Y. (2006). Direct and indirect bully-victims: Differential psychosocial risk factors associated with adolescents involved in bullying and victimization. Aggressive Behavior, 32(6), 551-569. https://doi. org/10.1002/ab.20155.

Mishna, F., Saini, M., \& Solomon, S. (2009). Ongoing and online: Children and youth's perceptions of cyber bullying. Children and Youth Services Review, 31(12), 1222-1228. https://doi. org/10.1016/j.childyouth.2009.05.004.

Muthén, L. K., \& Muthén, B. O. (2017). Mplus user's guide (8th ed.). Los Angeles, CA: Muthén \& Muthén.

Newman, M. L., Holden, G. W., \& Delville, Y. (2005). Isolation and the stress of being bullied. Journal of Adolescence, 28(3), 343-357. https://doi.org/10.1016/j.adolescence.2004.08.002.

Noret, N., Hunter, S. C., \& Rasmussen, S. (2018). The relationship between peer victimization, cognitive appraisals, and adjustment: A systematic review. Journal of School Violence, 17(4), 451-471. https://doi.org/10.1080/15388220.2017.1423492.

Olweus, D. (1978). Aggression in the schools: Bullies and whipping boys. London: Wiley.

Olweus, D. (1999). Sweden. In P. K. Smith, Y. Morita, J. Junger-Tas, D. A. Olweus, R. F. Catalano, \& P. T. Slee (Eds.), The nature of school bullying: A cross-national perspective (pp. 7-27). New York: Routledge.

Olweus, D. (2012). Cyberbullying: An overrated phenomenon? European Journal of Developmental Psychology, 9(5), 520-538. https ://doi.org/10.1080/17405629.2012.682358.

Olweus, D., \& Limber, S. L. (2018). Some problems with cyberbullying research. Current Opinion in Psychology, 19, 139-143. https ://doi.org/10.1016/j.copsyc.2017.04.012.

Paternoster, R., Brame, R., Mazerolle, P., \& Piquero, A. (1998). Using the correct statistical test for the equality of regression coefficients. Criminology, 36(4), 859-866. https://doi. org/10.1111/j.1745-9125.1998.tb01268.x.

Pierce, G. R., Sarason, I. G., \& Sarason, B. R. (1991). General and relationship-based perceptions of social support: Are two constructs better than one? Journal of Personality and Social Psychology, 61(6), 1028-1039. https://doi.org/10.1037/00223514.61.6.1028.

Pössel, P., Burton, S. M., Cauley, B., Sawyer, M. G., Spence, S. H., \& Sheffield, J. (2018). Associations between social support from family, friends, and teachers and depressive symptoms in adolescents. Journal of Youth and Adolescence, 47(2), 398-412. https ://doi.org/10.1007/s10964-017-0712-6.

Przybylski, A. K., \& Bowes, L. (2017). Cyberbullying and adolescent well-being in England: A population-based cross-sectional study. The Lancet Child and Adolescent Health, 1(1), 19-26. https://doi. org/10.1016/S2352-4642(17)30011-1.

Raskauskas, J., \& Huynh, A. (2015). The process of coping with cyberbullying: A systematic review. Aggression and Violent Behavior, 23, 118-125. https://doi.org/10.1016/j.avb.2015.05.019.

Reijntjes, A., Kamphuis, J. H., Prinzie, P., Boelen, P. A., van der Schoot, M., \& Telch, M. J. (2011). Prospective linkages between peer victimization and externalizing problems in children: A meta-analysis. Aggressive Behavior, 37, 215-222. https://doi. org/10.1002/ab.20374.

Reijntjes, A., Kamphuis, J. H., Prinzie, P., \& Telch, M. J. (2010). Peer victimization and internalizing problems in children: A metaanalysis of longitudinal studies. Child Abuse and Neglect, 34, 244-252. https://doi.org/10.1016/j.chiabu.2009.07.009.

Rigby, K. (2000). Effects of peer victimization in schools and perceived social support on adolescent well-being. Journal of Adolescence, 23(1), 57-68. https://doi.org/10.1006/jado.1999.0289.

Rigby, K., \& Slee, P. (1999). Suicidal ideation among adolescent school children, involvement in bully-victim problems, and perceived social support. Suicide and Life-Threatening Behavior, 29(2), 119-130. https://doi.org/10.1111/j.1943-278X.1999.tb01050.x.

Rivers, I., \& Noret, N. (2010). 'I h8 u': Findings from a five-year study of text and email bullying. British Educational Research Journal, 36(4), 643-671. https://doi.org/10.1080/01411920903071918.

Rosenberg, M., Houghton, S., Hunter, S. C., Zadow, C., Shilton, T., Wood, L., et al. (2018). A latent growth curve model to estimate electronic screen use patterns amongst adolescents aged 10 to 17 years. BMC Public Health, 18(1), 332-342. 
Rueger, S. Y., Malecki, C. K., \& Demaray, M. K. (2010). Relationship between multiple sources of perceived social support and psychological and academic adjustment in early adolescence: Comparisons across gender. Journal of Youth and Adolescence, 39(1), 47-61. https://doi.org/10.1007/s10964-008-9368-6.

Rueger, S. Y., Malecki, C. K., Pyun, Y., Aycock, C., \& Coyle, S. (2016). A meta-analytic review of the association between perceived social support and depression in childhood and adolescence. Psychological Bulletin, 142(10), 1017-1067. https://doi. org/10.1037/bul0000058.

Sarason, I. G., Levine, H. M., Basham, R. B., \& Sarason, B. R. (1983). Assessing social support: The social support questionnaire. Journal of Personality and Social Psychology, 44(1), 127-139. https ://doi.org/10.1037/0022-3514.44.1.127.

Slavin, L. A., \& Rainer, K. L. (1990). Gender differences in emotional support and depressive symptoms among adolescents: A prospective analysis. American Journal of Community Psychology, 18(3), 407-421.

Slonje, R., Smith, P. K., \& Frisén, A. (2017). Perceived reasons for the negative impact of cyberbullying and traditional bullying. European Journal of Developmental Psychology, 14(3), 295-310. https ://doi.org/10.1080/17405629.2016.1200461.

Smith, P. K., Mahdavi, J., Carvalho, M., Fisher, S., Russell, S., \& Tippett, N. (2008). Cyberbullying: Its nature and impact in secondary school pupils. Journal of Child Psychology and Psychiatry, 49(4), 376-385. https://doi.org/10.1111/j.1469-7610.2007.01846.x.

Solberg, M. E., \& Olweus, D. (2003). Prevalence estimation of school bullying with the Olweus Bully/Victim Questionnaire. Aggressive Behavior, 29(3), 239-268. https://doi.org/10.1002/ab.10047.

Stice, E., Ragan, J., \& Randall, P. (2004). Prospective relations between social support and depression: Differential direction of effects for parent and peer support? Journal of Abnormal Psychology, 113(1), 155-159. https://doi.org/10.1037/0021843X.113.1.155.

Tait, R. J., French, D. J., \& Hulse, G. K. (2003). Validity and psychometric properties of the General Health Questionnaire-12 in young Australian adolescents. Australian and New Zealand Journal of Psychiatry, 37(3), 374-381. https://doi.org/10.104 6/j.1440-1614.2003.01133.x.

Tanigawa, D., Furlong, M. J., Felix, E. D., \& Sharkey, J. D. (2011). The protective role of perceived social support against the manifestation of depressive symptoms in peer victims. Journal of School Violence, 10(4), 393-412. https://doi.org/10.1080/15388 220.2011 .602614$.

Tokunaga, R. S. (2010). Following you home from school: A critical review and synthesis of research on cyberbullying victimization. Computers in Human Behavior, 26(3), 277-287. https://doi. org/10.1016/j.chb.2009.11.014.

Ttofi, M. M., Farrington, D. P., Lösel, F., \& Loeber, R. (2011). Do the victims of school bullies tend to become depressed later in life? A systematic review and meta-analysis of longitudinal studies. Journal of Aggression, Conflict and Peace Research, 3(2), 63-73. https://doi.org/10.1108/17596591111132873.

Volk, A. A., Veenstra, R., \& Espelage, D. L. (2017). So you want to study bullying? Recommendations to enhance the validity, transparency, and compatibility of bullying research. Aggression and Violent Behavior, 36, 34-43. https://doi.org/10.1016/j. avb.2017.07.003.

Whitney, I., \& Smith, P. K. (1993). A survey of the nature and extent of bullying in junior/middle and secondary schools. Educational Research, 35(1), 3-25. https://doi.org/10.1080/001318893035010 1.

Wright, M. F. (2017). Cyber victimization and depression among adolescents with intellectual disabilities and developmental disorders: The moderation of perceived social support. Journal of Mental Health Research in Intellectual Disabilities, 10(2), 126-143. https ://doi.org/10.1080/19315864.2016.1271486.

Yeung, R., \& Leadbeater, B. (2010). Adults make a difference: The protective effects of parent and teacher emotional support on emotional and behavioral problems of peer-victimized adolescents. Journal of Community Psychology, 38(1), 80-98. https://doi. org/10.1002/jcop. 20353.

Publisher's Note Springer Nature remains neutral with regard to jurisdictional claims in published maps and institutional affiliations. 